\title{
Pneumonia Associada À Ventilação Mecânica Em Hospital Universitário.
}

\author{
Butzke, M.; Butzke, M.; Jimenez, L.F.; Marimon, M.M.; Uzeika, L.; Butzke, B.L.; \\ Apresentador: Maurício Butzke
}

\section{Resumo}

Introdução: A infecção hospitalar (IH) é um importante problema de saúde pública e é causa significativa de aumento de mortalidade e dos custos de hospitalizações. Nos pacientes submetidos a cuidado intensivo, a taxa de infecção hospitalar é ainda mais preocupante, sendo, nos EUA, três a cinco vezes mais comum do que em pacientes que não requerem esse tipo de cuidado. Dentre essas infecções, a pneumonia é responsável por cerca de $30 \%$ das IH, e dessas, as associadas à ventilação mecânica (PAVM) correspondem a $50 \%$. A PAVM é definida como uma infecção pulmonar que surge 48 a 72 horas após a intubação endotraqueal e instituição de ventilação mecânica invasiva. Suspeita-se de PAVM quando surge infiltrado pulmonar novo ou progressivo à radiografia de tórax, associado a presença de sinais clínicos e alterações laboratoriais como febre, leucocitose ou leucopenia e presença de secreção traqueal purulenta. Ela ocorre em $8 \%$ a $67 \%$ dos pacientes intubados e apresenta uma taxa de mortalidade que varia de $40 \%$ a $80 \%$. O objetivo do presente estudo é avaliar as taxas de PAVM, de maneira retrospectiva, no período dos últimos 10 anos no Hospital de Clínicas de Porto Alegre. Método: foi realizada análise de dados após coleta no Sistema de Informações Gerenciais de hospital universitário de
Porto Alegre. A taxa de PAVM foi calculada a partir da soma de PAVM, dividido pelo número de dias de uso de VM, multiplicado por mil. Resultados: A taxa de PAVM sofreu um decréscimo de 81,5\% nos 10 anos, sendo que em 2005, a taxa atingia 16,8 . Nos quatro anos subsequentes, o declínio deu-se de maneira lenta, atingindo 11,1 no ano de 2009 . No ano de 2010 houve uma queda de $42 \%$ em relaçaõ ao ano anterior da taxa, atingindo o valor de 6,5. O coeficiente continuou em decréscimo, atingindo o valor mais de 3,1 no ano de 2014. Conclusão: Observa-se uma tendência decrescente nas taxas de PAVM ao longo dos últimos dez anos. Esta mudança foi consequencia da educação e orientação dos profissionais de saúde, nas diversas áreas atuantes, principalmente em relação a técnicas de antissepsia. O maior impacto deu-se na transição dos anos de 2009 para 2010, ano em que foi implementado o protocolo da PAVM no referido hospital, uniformizando o manejo desta complicação, demonstrando a importância da padronização de técnicas para melhor assistência aos pacientes.

\section{Referência:}

Butzke, M.; Butzke, M.; Jimenez, L.F.; Marimon, M.M.; Uzeika, L.; Butzke, B.L.;. Pneumonia Associada À Ventilação Mecânica Em Hospital Universitário.. In: II Congresso Brasileiro de Medicina Hospitalar - II CBMH [= Blucher Medical Proceedings, vol.1, num.5] São Paulo: Editora Blucher, 2014. p.14

DOI 10.5151/medpro-II-cbmh-005 